\title{
Experimental food supplementation increases reproductive effort in the Variable Antshrike in subtropical Brazil
}

\author{
James J Roper ${ }^{\text {Corresp., }}{ }^{1,2}$ ， André M. X. Lima ${ }^{1}$ ， Angélica M. K. Uejima ${ }^{2,3}$ \\ 1 Programa de Pós Graduação em Ecologia e Conservação, Universidade Federal do Paraná, Curitiba, Paraná, Brazil \\ 2 Departamento de Zoologia, Universidade Federal do Paraná, Curitiba, Paraná, Brazil \\ 3 Centro Acadêmico de Vitória, Universidade Federal de Pernambuco, Vitória de Santo Antão, Pernambuco, Brazil \\ Corresponding Author: James J Roper \\ Email address: jjroper@gmail.com
}

Food limitation may interact with nest predation and influence nesting patterns, such as breeding season length and renesting intervals. If so, reproductive effort should change with food availability. Thus, when food is limited, birds should have fewer attempts and shorter seasons than when food is not limiting. Here we experimentally test that increased food availability results in increased reproductive effort in a fragmented landscape in the Variable Antshrike (Thamnophilus caerulescens) in southern Brazil. We followed nesting pairs in a naturally fragmented habitat and experimentally supplemented food for half of those pairs. Birds were seen, but evidence of nesting was never found in two small fragments, even though these fragments were larger than individual territories. Pairs with supplemented food were more likely to increase clutch size from two to three eggs and tended to renest sooner ( $20 \mathrm{~d}$ on average) than control pairs. Also, fragment size was associated with breeding patterns, although fragment replicates were unavailable. Nest duration, nest success and breeding season length were all greater, while renesting intervals were shorter, in the largest fragments. Simulations showed that only the largest fragments were able to have a net production of young. Food availability clearly influenced reproductive effort and as a consequence, because of the interaction with predation risk, forest fragments of varying sizes will have complex reproductive dynamics. 
Experimental food supplementation increases reproductive effort in the Variable Antshrike in subtropical Brazil

James J. Roper ${ }^{1,2}$, André M. X. Lima ${ }^{1}$ and Angelica M. K. Uejima ${ }^{2,3}$

${ }^{1}$ Programa de Pós-Graduação em Ecologia e Conservação

Universidade Federal do Paraná

Curitiba, Paraná, Brazil

${ }^{2}$ Departamento de Zoologia

Universidade Federal do Paraná

Curitiba, Paraná, Brazil

${ }^{3}$ Centro Acadêmico de Vitória

Universidade Federal de Pernambuco

Vitória de Santo Antão

Pernambuco, Brazil

Corresponding author: James J. Roper, , Telephone 5541 36730409, e-mail: jjroper@gmail.com 
1 ABSTRACT. Food limitation may interact with nest predation and influence nesting patterns,

2 such as breeding season length and renesting intervals. If so, reproductive effort should change

3 with food availability. Thus, when food is limited, birds should have fewer attempts and shorter

4 seasons than when food is not limiting. Here we experimentally test that increased food

5 availability results in increased reproductive effort in a fragmented landscape in the Variable

6 Antshrike (Thamnophilus caerulescens) in southern Brazil. We followed nesting pairs in a

7 naturally fragmented habitat and experimentally supplemented food for half of those pairs. Birds

8 were seen, but evidence of nesting was never found in two small fragments, even though these

9 fragments were larger than individual territories. Pairs with supplemented food were more likely

10 to increase clutch size from two to three eggs and tended to renest sooner ( $20 \mathrm{~d}$ on average) than

11 control pairs. Also, fragment size was associated with breeding patterns, although fragment

12 replicates were unavailable. Nest duration, nest success and breeding season length were all

13 greater, while renesting intervals were shorter, in the largest fragments. Simulations showed that

14 only the largest fragments were able to have a net production of young. Food availability clearly

15 influenced reproductive effort and as a consequence, because of the interaction with predation

16 risk, forest fragments of varying sizes will have complex reproductive dynamics. 
17 Introduction

18 Nest predation is the greatest cause of nesting failure among open nesting passerine birds and is

19 likely to have influenced avian life-history evolution (Nice 1957, Skutch 1949, 1985, Ricklefs

$201969,2000 a, b$, Roper et al. 2010). Food is also important and can limit reproduction in birds

21 (Ricklefs 1968, 2010, Martin 1987, Derbyshire et al. 2015) and may interact with predation,

22 thereby causing complex (behavioral and life history) responses to predation risk. For example,

23 the seasonal decline in clutch size in North American passerine birds may be due to reduced food

24 availability with each nesting attempt (Martin 1987, Milonoff 1991, Bauchau and Seinen 1997,

25 Castro et al. 2003). Where breeding seasons are long, nest predation rates are high and birds are

26 "income breeders" (that is, food availability at the time of egg production limits egg production,

27 rather than stored reserves that fuel egg production in "capital breeders"), food availability may

28 limit annual reproductive success because of its influence on both the number of nesting attempts

29 and individual nest success (Soler and Soler 1996, Davis et al. 2005, Ricklefs 2010, Roper 2005,

30 Stephens et al. 2014). Lower food abundance can result in fewer renesting attempts following

31 predation (Rolland et al.1998, Roper et al. 2010, Zanette et al. 2011) and more food may increase

32 nesting success since both young and parents may be well-fed by fewer trips to the nest, thereby

33 reducing the potential effect of visitation rate on predation risk (Holmes et al. 1992, Kuituken

34 and Makinen 1993, Soler and Soler 1996, Martin et al. 2011). Thus, experimentally increased

35 food abundance may reduce the incubation period (if it is flexible and not genetically

36 constrained), and reduce nest predation (because of fewer trips to and from the nest), increase

37 growth rates and permit additional nesting attempts in species that usually have only one

38 successful nest per year (Martin 1987, Davis and Graham 1991, Meijer and Drent 1999, Castro et

39 al. 2003, Roper et al. 2010). 
Food abundance may interact synergistically with fragment size, predation risk and other

41

42

43

44

45

46

47

48

49

50

51

52

53

54

55

56

57

58

59

60

61

62

causes of nest failure (Gates and Gysel 1978, Donovan et al. 1995, 1997, Burke and Nol, 1998,

Batáry and Báldi 2004, Huhta et al. 1998, 2004, Abensperg-Traun et al., 2000, but see

Tewksbury et al. 1998). However, even though both predation risk and food abundance may be independently influenced by fragment size (Askins, 1995, Melo and Marini 1997, Weinberg and Roth 1998, Stratford and Stouffer 2001, Fort and Otter 2004, Tewksbury et al. 2006), declining food abundance may still influence the likelihood of repeated nesting attempts following predation due to a reproductive cost or decreased survival (Ruiz-Gutiérrez et al. 2008). Thus, annual reproductive success is expected to decline due to an inverse relationship between both predation risk and food abundance with fragment size. When predation rates are high renesting is even more important for annual reproductive success (Roper 2005, Roper et al. 2010). Therefore, a consequence of high predation rates, renesting rates may decline and brood reduction may occur more often in smaller fragments due to reduced food abundance (Suarez et al. 1997, Huhta et al. 1998, Zanette and Jenkins 2000, Barding and Nelson, 2008, Hinam and St.Clair 2008).

The landscape of fear concept (Bleicher 2017) may be applicable in fragmented landscapes if the probability of nest predation is associated with fragment size. Thus, we may expect complex interactions and responses to both food abundance and nest predation in birds that are found in fragmented landscapes (Zanette et al., 2011). How those interactions are manifest in nature remain to be studied because of their complexity.

Here, we examine nesting success and experimentally manipulated food abundance in a fragmented landscape to test for the importance of food abundance and predation risk and their interactions in a subtropical understory-nesting bird, the Variable Antshrike (Thamnophilus caerulescens, Vieillot, 1816) in southern Brazil. The Variable Antshrike was chosen because the 
63 genus Thamnophilus has been studied in the tropics and so its breeding biology may be

64 compared with other species in the genus (Roper and Goldstein 1997, Roper 2003, 2005;

65 Tarwater 2008, Roper et al. 2010, Tarwater and Brawn 2010). Also, it is a relatively common, 66 yet poorly studied species of the Atlantic Forest southeastern South America (Oniki and Willis

67 1999). Finally, visits to the study area always found antshrikes in the visited forest fragments.

68 We predict that food supplementation will result in increased reproductive effort, which may be

69 manifest as increased number of nesting attempts, reduced intervals between nesting attempts,

70 greater nesting success and combinations thereof (Ruffino et al. 2014).

71

72

73

74

75

\section{METHODS}

Study Area.---Nesting in the Variable Antshrike was studied in a region of natural forest fragments separated by open grassland and savanna, Vila Velha State Park $\left(25.25^{\circ} \mathrm{S}, 50.08^{\circ} \mathrm{W}\right.$, $\sim 1000 \mathrm{~m}$ above sea level) in Paraná, southern Brazil (Figs. 1, 2). The entire park comprises 3,122 ha and the forest fragments are typical of the mixed Atlantic Forests of Brazil, dominated by Araucaria angustifolia. Natural fragments range in size from $1-450$ ha and are separated from each other by a minimum of $50 \mathrm{~m}$. We selected five fragments (with $>100 \mathrm{~m}$ separation from each other, and from other fragments) with areas of 4,23,24, 112 and 214 ha to include the approximate range of local fragment size and maintain the $>100 \mathrm{~m}$ distance between fragments. Due to time constraints, it was not feasible to include more fragments in this study, hence we will emphasize the analysis of food supplementation. 
86 that begin in October and end in January of the subsequent year. The antshrike is a sexually

87 dimorphic, insectivorous, understory bird. As in other members of the family, it is territorial,

88 monogamous (as far as is known), and nests in the forest understory, building an open-cup nest

89 in horizontal forks of shrubs and saplings usually less than $3 \mathrm{~m}$ above the ground, as is typical of

90 the genus (Oniki 1975, Ridgely and Tudor 1994, Roper 2000, 2005). Variable Antshrikes lay

91 clutches of two or three eggs (see below) and both parents contribute in all aspects of

92 reproduction, including nest construction, incubation, feeding nestlings and post-fledging care

93 (Oniki and Willis 1999, Zimmer and Isler 2003). Details of the breeding season, such as start and

94 end of the breeding season, number of clutches per year, variation in clutch size, are all very

95 poorly know, and will be reported here for the first time.

96 We captured Variable Antshrikes using mist-nets and banded each with a unique

97 combination of colored leg bands and a metal band provided by CEMAVE (the Brazilian

98 governmental agency that oversees bird studies). Because we wished to know annual

99 reproductive success, we followed banded pairs to find nests (each year attempting to capture

100 more pairs). Song playbacks to attract birds to the nets were sparingly used when pairs were

101 difficult to find. Nests were checked every 2 -3 days until they either succeeded (when one or

102 more young fledged) or failed (when no young fledged). Predation was assumed to be the cause

103 of failure when eggs or nestlings disappeared prior to the fledging date and adults were not seen

104 with young birds away from the nests. All methods and animal manipulation followed standards

105 of ethics under Brazilian law.

106

107 Experimental food supplementation.---To test the importance of food on nesting success about

108 half of the pairs found in each fragment were randomly chosen to receive supplemental food. In 
109 these territories, food (mealworms, Tenebrionidae) was placed in a small dish $(\sim 10 \mathrm{~cm}$ in

110 diameter, used for feeding cage birds, about the same diameter as a nest; Zimmer and Isler 2003,

111 Londoño et al. 2008) attached to a branch within $5 \mathrm{~m}$ of the first active nest found for each pair.

112 We did not attempt to quantify how much food we gave, but placed $\sim 10$ mealworms in each dish

113 each day, until fledging or nest failure. If a nest failed and when a new nest of that same pair was

114 found, the dish was moved to about $5 \mathrm{~m}$ from the new nest and food was again made available.

115 While the birds were accustomed to feeding from the dish where it was, we moved it closer to

116 the new nest for both logistical reasons and to help ensure that the same pair fed from the dish.

117 We visually confirmed that all pairs with supplemented food took the offered mealworm larvae.

118 Assignment of experimental treatments were constant (each pair was used for only one

119 treatment) throughout the study. Because food supplementation began with the first nest attempt

120 found for pairs in the supplementation treatments, food supplementation was not important in

121 first nest initiation (see below). Also, because the food dish was small and inconspicuous, we

122 assumed that the presence of a dish itself was unimportant, therefore we did not put empty dishes

123 in the control territories.

124

125 Reproductive effort--- Effort was measured in four main ways: the number of nesting attempts,

126 length of the renesting interval, breeding season length and nesting success. Because our study

127 area is fragmented, we also tested for interactions with fragment size (area) as a covariate with

128 interaction terms when sample sizes allowed. Four potential outcomes of the experiment were

129 possible with respect to effort: 1) effort is independent of food treatment and fragment size, 2)

130 effort increases with supplemented food but is independent of fragment size, 3) effort is 
131 independent of food treatment but dependent on fragment size and 4) effort increases with both

132 supplemented food and fragment size.

133 We tested these possibilities with nesting success using the program MARK (version 6.0).

134 MARK permits the estimation of daily survival rate that may be compared (using $\triangle \mathrm{AICc}$ to

135 select the best model) among groups (White and Burnham, 1999, Dinsmore et al. 2002). We

136 compared renesting intervals, number of renesting attempts, among food treatments and

137 fragments of different size and their possible interactions using analysis of variance (ANOVA)

138 or analysis of covariance (ANCOVA) when appropriate. Only the intervals following failed

139 nesting attempts were used in this analysis because the interval after success involves an

140 extended period of post-fledging care. We compared clutch size among treatments (both

141 fragment size and food supplementation) using log-likelihood ratio test $(G)$.

142 Finally, while we predicted that annual productivity should reflect effort, in practice,

143 annual productivity is a complex interaction between predation rate and number of nesting

144 attempts (Roper et al. 2010). Once a nest is successful, parents must then spend some amount of

145 time in parental care of fledglings. Also, if the number of successes are limited, even in relatively

146 poor conditions, by renesting pairs may finally beat the odds and successfully nest (Roper 2005).

147 Thus, to examine how annual productivity might change with food abundance and the correlated

148 variables (renesting intervals, breeding season length) we simulated the annual breeding cycle

149 (see Roper et al. 2010) using the parameters found in this study (daily nest survival rates,

150 renesting intervals and clutch size by fragment size), and generated 100 replicates of 30 pairs

151 under each combination of conditions. We compared annual productivity under the combinations

152 of conditions using multivariate analysis of variance (MANOVA). Under the assumption that the 
153 parameters measured and estimated in this study reflect actual field conditions, this simulation

154 allows generating larger samples that are then comparable (Roper et al. 2010).

155

156

\section{RESULTS}

157 During preliminary censuses prior to beginning of this experiment, we found antshrikes in all

158 fragments. However, while capturing and marking birds, we never captured antshrikes nor found 159 evidence of nesting in the smallest fragment (4 ha), even though observations suggest that their

160 territory size can be much smaller ( 1 ha, J. Roper, pers. Observ.). We state this for two reasons:

161 1) we attempted replicates of small fragments, 2) to demonstrate that small fragments may be

162 unsuitable, perhaps for reasons we will describe here. Nine females were captured in the larger

163 of the two small fragments (23 ha), but never again seen again in the fragment in which they

164 were captured. Four of them were later found and followed in the 112 ha fragment where they

165 remained in the same territory for the duration of this study. Nests (a total of 103) were

166 only found in use in the 24,112 and 214 ha fragments, and so food supplementation was only

167 possible in those fragments. A total of three pairs were followed in the 24 ha fragment, and eight

168 pairs each in the 112 and 214 ha fragments. Once pairs were marked and followed, most pairs

169 remained together for the duration of this study. When an individual disappeared, it was replaced

170 by a previously unbanded bird and no "divorce" or mate-switching was ever observed.

171

172 Timing of Breeding ---We describe the second two years because during the first year we spent

173 time early in the season capturing birds and may have missed some nests. During the next two

174 years of this study the breeding season began on 26 Oct 2001 (first egg laid the following day)

175 and 9 Oct 2002 (with the first of two eggs) and ended on 26 Jan 2002 (last nest found with 2 
176 eggs) 9 Jan 2003 (found with two eggs, 92 days). Breeding season length varied by fragment size.

177 Pairs in the 112 ha fragment had the longest season length (91 d in 2001, $89 \mathrm{~d}$ in 2002), followed

178 by pairs in the 214 ha ( $77 \mathrm{~d}$ in $2001,82 \mathrm{~d}$ in 2002) and $24 \mathrm{ha}(42 \mathrm{~d}$ in $2001,48 \mathrm{~d}$ in 2002).

179

Reproductive effort and success.---Nesting success (as daily nest survival rate) was lowest in the

18111 nests (all of which failed) in $2000\left(0.836\right.$ day $\left.^{-1}, \mathrm{SE}=0.045\right)$. We do not include those nests in

182 analysis because it being the first year of study, when we were also actively capturing birds, we

183 cannot be certain that our activities did not affect success, and sample size was small. In

184 subsequent years, the field season began with banded birds, so we captured less often, thereby

185 reducing our potential influence on nesting. Thus, in $2001\left(0.911\right.$ day $\left.^{-1}, \mathrm{SE} 0.014, \mathrm{~N}=41\right)$ and

$1862002\left(0.935\right.$ day $\left.^{-1}, \mathrm{SE}=0.011, \mathrm{~N}=51\right)$, daily survival rates were similar. None of the seven

187 nests was successful in the small (24 ha) forest fragment. Five of 67 nests ( $8 \%)$ were successful

188 in the 112 ha fragment and 17 of 29 nests (59\%) were successful in the 214 ha fragment (Table

189 1). Daily survival rate (DSR) was consequently greatest in the large fragment $\left(0.97 \mathrm{day}^{-1}, \mathrm{SE}=\right.$

190 0.01), which was greater than that of the other two fragments (in which DSR was similar: 112 ha

$191=0.88$ day $\left.^{-1}, \mathrm{SE}=0.01,24 \mathrm{ha}=0.85 \mathrm{day}^{-1}, \mathrm{SE}=0.05, \mathrm{P}<0.05\right)$. The large differences in daily

192 survival rate among the fragments dominates the relationship between food abundance and

193 nesting success and the model with only forest fragment size as a predictor variable and the

194 model including supplemented food and fragment size were similar (other models had $\triangle \mathrm{AICc}>$

19510 , likelihood ratio test, $\chi^{2}=5.0, \mathrm{SE}=3.0, \mathrm{P}>0.05$, Table 2, Fig. 2A).

196 The combined effect of food supplementation and forest fragment size (with no

197 interaction) explained $37 \%$ of the variance in number of nesting attempts per pair per year, with

$19826 \%$ explained by supplementation and $11 \%$ by fragment size $\left(\mathrm{F}_{3,35}=8.58, \mathrm{R}^{2}=0.37, \mathrm{P}<\right.$ 
199 0.001). With supplemented food, the number of nesting attempts increased to an average of 2.17 200 nests year-1 $(\mathrm{SE}=0.47)$ as compared to 1.3 nests $(\mathrm{SE}=0.13)$ in controls $\left(F_{3,38}=8.5, \mathrm{r}^{2}=0.37, \mathrm{p}\right.$

$201<0.05$ ). The 112 ha fragment had the greatest number of attempts pair ${ }^{-1}$ year $^{-1}$ (least squares

202 mean $=3.2, \mathrm{SE}=0.2$, maximum $=5)$ followed by the 214 ha fragment $(1.95, \mathrm{SE}=0.24, \max =$

$2033)$ and 24 ha fragment $($ mean $=1.75, \mathrm{SE}=0.45, \max =2, \mathrm{P}<0.05)$.

204 Variable Antshrikes may renest after both failed and successful nests. In all years, pairs

205 varied from no renesting attempts (3 pairs, one both years), one renesting $(\mathrm{N}=16)$, two $(\mathrm{N}=9)$,

206 three $(\mathrm{N}=5)$, and four $(\mathrm{N}=4)$, for a total of 65 renesting attempts. Overall, renesting occurred

207 from $3-54$ days after failure (median $=15$ days $)$ and $11-45$ days after success $($ median $=26$

208 days, Table 1). We do not have data that indicate whether the renesting after success was

209 influenced by post-fledging mortality or dispersal.

210 Renesting interval was independent of year (ANOVA, $F_{2,52}<1, \mathrm{P}>0.5$ ) and so we

211 combined years in the following analysis. Renesting interval after unsuccessful nests was

212 influenced by both, food supplementation and fragment size with no interaction (ANCOVA,

213 adjusted $\mathrm{R}^{2}=0.87, F_{3,47}=110.7, \mathrm{P}<0.001$, Table 1 , Fig. 2B). Of the variance explained by the

214 full model (87\%), 65\% was due to the addition of food and the remaining $12 \%$ was explained by

215 fragment size. In control territories, renesting interval was shorter by $7.8 \mathrm{~d}$ in the large (214 ha,

$21628 \mathrm{~d}$ ) versus the small (24 ha, $35 \mathrm{~d})$ fragment which was similar to the 112 ha (34 d) fragments.

217 In food supplemented territories, renesting in the large fragment and medium fragment (15 and

$21812 \mathrm{~d}$ respectively) were similar, and less than that in the small fragment (22 days, Table 1 ).

219 Clutch size varied between $2-3$ eggs, and 23 of the 25 three-egg clutches followed food

220 supplementation. Only 2-egg clutches were found in the smallest fragment ( $n=7$ clutches), 2 ( $n$

$221=51)$ and $3(n=16,24 \%)$ egg clutches in the 112 ha fragment and $2(n=20)$ and 3 egg $(n=9$, 
$22231 \%$ ) clutches in the 214 ha fragment. Due to limited sample size, we could not test an additional

223 effect of fragment size on clutch size.

224 As predicted, the probability of renesting increased in food supplemented pairs, with an

225 interaction with fragment size $\left(\mathrm{F}_{5,174}=29.0, \mathrm{R}^{2}=0.44, \mathrm{P}<0.0001\right)$. In the full model, $21 \%$ of

226 the $44 \%$ of the variance was explained by food supplementation, $18 \%$ by fragment size, and the

227 remaining $5 \%$ by the interaction. In the simulations, up to five attempts were possible (Fig. 3)

228 and annual productivity was always greatest with supplemented food (Table 3, Fig. 4). Also,

229 multiple successful nests within a year were only likely to occur in the food supplemented

230 scenarios (Table 3), and the four pairs that had two successful nests in 2002 all received

231 supplemented food. Failure to reproduce in a give breeding season was likely to occur in a large

232 proportion of the control pairs and occurred in 5 (2001) and 4 (2002) control pairs, and 3 (both 233 years) fed pairs.

\section{DISCUSSION}

In this first experimental test of food supplementation as an influence of parental nesting effort in neotropical birds, three trends clearly demonstrate that food abundance can influence effort and, as a consequence, annual reproductive success. When food was added, 1) pairs renested after shorter intervals, 2) pairs increased their number of nesting attempts per year, and 3) females laid larger clutches. Further, preliminary evidence suggests that fragment size also matters even

241 though an ideal fragmentation study should include replicates of fragments (unavailable in this

242 study area). Breeding began sooner and ended later in larger fragments, nesting success was

243 greatest in the largest fragment, all nests failed in the smallest fragment, and all nest failure was

244 due to predation. Also, we emphasize that two smaller fragments (in which we previously found 
245 singing birds) had no nesting attempts and during this study, birds were not consistently found in 246 these fragments, thus indicating that small fragments are problematic.

Food supplementation reduced renesting intervals and so with added food, more rapid

248

249

250

251

252

253

254

255

256

257

258

259

260

261

262

263

264

265

266

267

renesting, and consequently more nesting attempts summed to greater annual success (Roper 2005, Roper et al. 2010, Ruffino 2014). Food availability may also interact with other variables (self-maintenance, time incubating, etc.) during nesting (Londoño et al. 2008), but we did not measure behavior per se, and so we cannot comment on exactly how food influenced nesting aside from nesting intervals. Timing of breeding as a response to food abundance is clearly important and can explain a decline in clutch size over time (Murphy 1986). Also, high expected predation can reduce reproductive effort (Zanette et al., 2003, Zanette et al., 2011). However, in birds with potentially long breeding seasons and high predation risk, perhaps the best strategy is repeated nesting attempts (Roper 2005). If so, then food abundance is especially likely to be important to allow repeated investment in eggs. Combining breeding season length with renesting intervals, we can see that $\sim 38$ days in the 24 ha (small) fragment with $19-37$ day renesting intervals, a maximum of two attempts can fit into a season. Indeed, only two attempts at most were initiated by pairs in that small fragment. With food supplementation in larger fragments, the combined benefits of increased clutch size, longer breeding season and more rapid renesting result in as many as five attempts (in the 112 ha fragment) and much greater potential reproductive success (in the 214 ha fragment). Thus, in the simulation, annual productivity may vary from 1.5 (control) to 3.1 (fed) fledglings pair $^{-1} \mathrm{yr}^{-1}$, with $\leq 30 \%$ of the population being unsuccessful in the 214 ha fragment, in comparison with annual productivity always less than 1 fledgling pair $^{-1} \mathrm{yr}^{-1}$ and $>90 \%$ unsuccessful in the 24 ha fragment and $>75 \%$ unsuccessful in the 112 ha fragment (Table 3). In our simulation, when food was supplemented in the large 
268 fragment, all "populations" of 30 birds had an average predicted fecundity $\geq 1$ (variable over the 269 range of 1 to 4$)$, with the food supplmented treatments having the greatest values ( $>2.5)$. In stark

270 contrast, in both smaller fragments, average predicted fecundity was always less than 1,

271 regardless of supplemented food (even though when food is supplemented, success still

272 increases, Fig. 4). The irregular curves in Figure 4, rather than smooth lines, are due to the

273 complex interaction between the number of days a nest survives, renesting intervals and breeding

274 season length. For example, when nest success is greater, nests that fail last longer on average

275 than at lower success rates, thereby reducing future opportunities to renest. This leads us to

276 conclude that high predation rates can overwhelm the effects of food abundance.

Food abundance also influenced clutch size as has long been suggested (Lack 1947, 1948,

278 1949, Ricklefs 1968, 1980, 2000, 2010) and here, all but two of the 253 -egg clutches (8\%)

279 followed food supplementation. Also, 3-egg clutches were only found in the two largest

280 fragments. Elsewhere at the same latitude, Variable Antshrikes can lay 3-egg clutches and at

281 least one has been found with four eggs (J. J. Roper, pers. obs.). Thus, the more common 2-egg

282 clutch in this study may reflect local food limitation and also emphasizes the importance of the

283 synergy between food and predation for nesting success.

The association between supplemental food and increased clutch size in the large

285 fragments suggests complex associations between forest fragment size, food abundance and 286 reproductive effort (Donovan et al. 1995, Robinson et al. 1995, Burke and Nol 1998, Vergara

287 and Simonetti, 2004, Lloyd et al. 2006, Tielemann et al. 2008). In some experimental studies, 288 supplemental food resulted in no change in clutch size, which was then attributed to inflexibility 289 in the genetic determination of clutch size (Meijer and Drent 1999, Bourgault et al. 2009). In our 290 study, the impact of additional food was clear because supplementation began with the first nest 
291 attempt, and the increase in clutch size usually occurred after that first attempt when food was

292 added. This result was different than expected for the Variable Antshrike because other species

293 of Thamnophilus have a fixed clutch size of two (Oniki 1975, Skutch 1985, Roper and Goldstein

294 1997, Oniki and Willis 1999, Roper 2005, Roper et al. 2010).

295 Decreased nest predation rate in the largest fragment may be the result of several

296 interactions (Sinclair et al. 2005, Cain et al. 2006, Vergara and Hahn 2009, Zanette et al. 2011).

297 Greater food abundance may have allowed reduced activity at nests (Skutch 1949, 1985) and

298 greater nest attentiveness (Chalfoun and Martin 2007). Greater distances to the edge in the large

299 fragment may have reduced the likelihood of predators from the matrix between fragments from

300 reaching the nests (Gates and Gysel 1978, Duca et al. 2001, Sinclair et al. 2005), although these

301 fragments are natural and it is not clear whether the matrix has more or fewer predators than the

302 forest itself. Alternatively, greater habitat heterogeneity within the larger fragments may reduce

303 predator efficiency at finding nests by impeding the development of a "search image" by the

304 predator (Martin and Roper 1988). Perhaps simply increasing food abundance generates the

305 perception that predation risk is lower, thereby allowing the increased clutch size (Zanette et al.

306 2011). Also, greater nest predation risk in smaller fragments may have created a different

307 landscape-of-fear which contributed to a shorter breeding season length and fewer attempts than

308 the larger fragment (Zanette et al. 2011, Bleicher 2017).

309 Here, with this food supplementation experiment in a tropical understory bird, we

310 demonstrate a clear increase in reproductive effort with increased food availability. Evidence

311 suggests that food abundance interacts with forest fragment size, even in natural forest

312 fragments, resulting in reduced fecundity, reduced time in which to breed, and consequent loss of

313 population viability, especially when predation risk is greater in the smaller fragments (Porneluzi 
314 and Faaborg, 1999). The combined effect of renesting faster, renesting more often and a longer

315 breeding season results in the likelihood of nearly $100 \%$ of successful nesting every year. Thus,

316 reproductive effort can increase with even a small addition of food in a fragmented forested

317 landscape in southern Brazil, which suggests that annual reproduction may also vary widely

318 among years, if food abundance also varies.

319

320

\section{ACKNOWLEDGMENTS}

321 We would like to thank the several field assistants that helped monitor nests and endured the

322 long walks between forest fragments. Thanks to Vila Velha State Park for their help both in

323 allowing the study in the park as well as providing housing and additional help. We thank

324 anonymous reviewers for their constructive suggestions.

325

326

LITERATURE CITED

327

328

329

330

331

332

333

334

335

Abensperg-Traun, M., G.T. Smith and B.Y. Main. 2000. Terrestrial arthropods in a fragmented landscape: a review of ecological research in the western Australian central wheatbelt. Pacific Conservation Biology 6: 102-119.

Askins, R.A. 1995. Hostile landscapes and the decline of migratory songbirds. Science 267:11956-11957.

Barding, E.E. and T.A. Nelson. 2008. Raccoons use habitat edges in north Illinois. American Midland Naturalist 159: 394-402.

Batáry, P. and A. Báldi. 2004. Evidence of an edge effect on avian nest success. Conservation Biology 18: 389-400. 
336 Bauchau, V. and I. Seinen. 1997. Clutch desertion and re-nesting in pied flycatchers: an

337

338

339

340

341

342

343

344

345

346

347

348

349

350

351

352

353

354

355

356

357 experiment with progressive clutch removal. Animal Behavior 54: 153-161.

Bleicher, S.S. 2017. The landscape of fear conceptual framework: definition and review of current applications and misuses. PeerJ 5:e3772; DOI 10.7717/peerj.3772

Bourgault, P., P. Perret and M.M. Lambrechts. 2009. Food supplementation in distinct Corsican oak habitats and the timing of egg laying by Blue tits. Journal of Field Ornithology 80: 127-134.

Burke, D.M., and Nol, E. 1998. Influence of food abundance, nest-site habitat, and forest fragmentation on breeding ovenbirds. The Auk 115:96-104.

Cain, A. W.III, K.S. Smallwood, M.L. Morrison and H. L. Loffland. 2006. Influence of Mammal activity on nesting success of passerines. Journal of Wildlife Management 70: 522-531.

Castro, I., D.H. Brunton, K.M. Mason, B. Ebert and R. Griffiths. 2003. Life history traits and food supplementation affect productivity in a translocated population of the endangered Hihi (Stitchbird, Notiomis cincta). Biological Conservation 114: 271-280.

Chalfoun, A.D. and T.E. Martin. 2007. Latitudinal variation in avian incubation attentiveness and a test of the food limitation hypothesis. Animal Behavior 73: 579-585.

Creel, S. 2018. The control of risk hypothesis: reactive vs. proactive antipredator responses and stress-mediated vs. food-mediated costs of response. Ecology Letters 21:947-956.

Davis, W.J. and D.J. Graham. 1991. The influence of food on reproductive strategies in a monogamus kingfisher, (Chloroceryle amazona). Auk 108:780-798.

Davis, S.E., R.G. Nager and R.W. Furness. 2005. Food availability affects adult survival as well as breeding success of parasitic jaegers. Ecology 86: 1047-1056. 
358 Derbyshire, R., Strickland, R. \& Norris, D. R. 2015. Experimental evidence and 43 years of 359 monitoring data show that food limits reproduction in a food-caching passerine. Ecology $360 \quad 96: 3005-3015$.

361 Dinsmore, S. J., G. C. White, and F. L. Knopf. 2002. Advanced techniques for modeling avian 362

363 Donovan, T.M., F.R. Thompson, J. Faaborg and J.R. Probst. 1995. Reproductive success of 364 migratory birds in habitat sources and sinks. Conservation Biology 9: 1380-1395.

Donovan, T.M., P.W. Jones, E.M. Annand and F.R. Thompson, III. 1997. Variation in localscale edge effects: mechanisms and landscape context. Ecology 78: 2064-2075.

Duca, C., J. Gonçalves and M.A. Marini. 2001. Predação em ninhos artificiais em fragmentos de matas de Minas Gerais, Brasil. Ararajuba 9: 113-117.

Ekman, J., S. Eggers, M. Griesser and H. Tegelström. 2001. Queuing for preferred territories: delayed dispersal of Siberian Jays. Journal of Animal Ecology 70: 317-324.

Fort, K. T. and K. A. Otter. 2004. Effects of habitat disturbance on reproduction in black-capped Chickadees (Pecile atricapillus) in northern British Columbia. Auk 121: 1070-1080.

Gates, J.E. and L.W. Gysel. 1978. Avian nest dispersion and fledgling success in field-forest ecotones. Ecology 59: 871-883.

Hinam, H.L. and C.C. St.Clair. 2008. High levels of habitat loss and fragmentation limit reproductive success by reducing home range size and provisioning rates of Northern saw-whet owls. Biological Conservation 141: 524-535.

Holmes, R.T., T.W. Sherry, P.P. Marra and K. E. Petit. 1992. Multiple brooding and productivity of a neotropical migrant, theblack-throated blue warbler (Dendroica caerulescens), in an unfragmented temperate forest. Auk 109: 321-333. 
381 Huhta, E., J. Jokimäki and P. Rahko. 1998. Distribution and reproductive success of the Pied 382 Flycatcher Ficedula hypoleuca in relation to forest patch size and vegetation 383 characteristics: the effect of scale. Ibis 140: 214-222.

384 Huhta, E., J.T. Aho, A. Jäntti, P. Suorsa, M. Kuituken, A. Nikula and H. Hakkarainen. 2004. 385 Forest fragmentation increases nest predation in the Eurasian Treecreeper. Conservation $386 \quad$ Biology 18: 148-155.

387 Kuituken, M. and M. Makinen. 1993. An experiment on nest-site choice of the common 388 treecreeper in fragmented Boreal forest. Ornis Fernnica 70: 163-167.

389 Lack, D. 1947. The significance of clutch size. Ibis 89: 302-352.

390 Lack, D. 1948. Natural selection and family size in the starling. Evolution 2: 95-110.

391 Lack, D. 1949. Comments on Mr. Skutch's paper on clutch size. Ibis 91: 455-458.

392 Lima, A.M.X. de and J.J. Roper, 2009. Population dynamics of the black-cheeked gnateater

393 (Conopophaga melanops, Conopophagidae) in southern Brazil. Journal of Tropical $394 \quad$ Ecology 25: 605-613.

395 Lloyd, P., T.E. Martin, R.L. Redmond, M.M. Hart, U. Langner and R. D. Bassar. 2006.

396 Assessing the influence of spatial scale on the relationship between avian nesting success 397 and forest fragmentation: a case study, p. 255-269. In: J. Wu, K. B. Jones, H. Li, and O. 398 Loucks, (Eds.). Scaling And Uncertainty Analysis In Ecology: Methods and Applications $399 \quad$ Springer, Netherlands.

400 Londoño, G. A., Levey, D.J. and S. K. Robinson. 2008. Effects of temperature and food on 401 incubation behaviour of the northern mockingbird, Mimus polyglottos. Animal Behavior 402 76: $669-677$. 
403 Martin, T. E. 1987. Food as a limitation breeding birds, a life history perspective. Annual $404 \quad$ Review in Ecology and Systematics 18: 453-487.

405 Martin, T.E. and J. J. Roper. 1988. Nest predation and nest site selection in a western population 406 of the Hermit Thrush. Condor 90: 51-57.

407 Martin, T.E., P. Lloyd, C. Bosque, D.C. Barton, A.L. Biancucci, Y. Cheng and R. Ton. 2011. 408 Growth rate variation among passerine species in tropical and temperate sites: an 409 antagonistic interaction between parental food provisioning and nest predation risk. Evolution 65: 1607-1622.

411 Meijer, T. and R. Drent. 1999. Re-examination of the capital and income dichotomy in breeding 412 birds. Ibis 141: 399-414.

413 Melo, C. and M. A. Marini. 1997. Predação de ninhos artificiais em fragmentos de matas do $414 \quad$ Brasil Central. Ornitologia Neotropical 8: 7-14.

415 Milonoff, M. 1991. Renesting ability and clutch size in precocial birds. Oikos 62: 189-194.

416 Murphy, M. T. 1986. Temporal components of reproductive variability in Eastern Kingbirds 417 (Tyrannus tyrannus). Ecology 67: 1483-1492.

418 Nice, M.M. 1957. Nesting success in altricial birds. Auk 74: 305-321.

419 Oniki, Y. 1975. The behavior and ecology of Slaty Antshrikes (Thamnophilus punctatus) on 420 Barro Colorado Island, Panamá Canal Zone. Anais Academia brasileira de Ciência 47: 471-515.

422 Oniki, Y., and Willis, E.O. 1999. Single Nestling Care and Male Abandoning in Variable

423 Antshrikes Thamnophilus Caerulescens, with Notes on Excess Roadside Clearing. 424 Ornitologia Neotropical 10: 91-94. 
425 Porneluzi, P.A. and J. Faaborg. 1999. Season-long fecundity, survival and viability of ovenbirds 426 in fragmented and unfragmented landscapes. Conservation Biology 13: 1151-1161.

427 Ricklefs, R. E. 1968. On the limitation of brood size in passerine birds by the ability of adults to 428 nourish their young. Proceedings of the National Academy of Sciences, 61: 847-851.

Ricklefs, R.E. 1969. An analysis of nesting mortality in birds. Smithsonian Cont. Zoology 9: 1430 48.

431 Ricklefs, R.E. 1980. Geographical variation in clutch size among passerine birds: Ashmole's hypothesis. The Auk 97:38-49

433

434

435

436

437

438

439

440

441

442

443

444

445

446

447

Ricklefs, R.E. 2000a. Lack, Skutch, and Moreau: the early development of life-history thinking. Condor 102: 3-8.

Ricklefs, R.E. 2000b. Density dependence, evolutionary optimization, and the diversification of avian life histories. Condor 102: 9-22

Ricklefs, R.E. 2010. Parental Investment and Avian Reproductive Rate: Williams's Principle Reconsidered. The American Naturalist 175: 350-361.

Robinson, W.D., Robinson, T.R., Robinson, S.K., and Brawn, J.D. 2000. Nesting Success of Understory Forest Birds in Central Panama. Journal of Avian Biology 31:151-64. doi:10.1034/j.1600-048X.2000.310207.x.

Robinson, W.D., Hau, M., Klasing, K.C., Wikelski, M., Brawn, J.D., Austin, S.H., Tarwater, C.E., and Ricklefs, R.E. 2010. Diversification of life histories of new world birds. The Auk 127: 253-262.

Rolland, C., E. Danchin and M. Defraipont. 1998. The evolution of coloniality in birds in relation to food, habitat, predation, and life-history traits: A comparative analysis. American Naturalist 151: 514-529. 
448 Roper, J.J. 2000. Experimental analysis of nest-sites and nest predation for a neotropical bird:

449 stuck between a rock and a hard place. Ararajuba 8: 85-91.

450 Roper, J.J. 2005. Try and try again: Nest Predation Favors Persistence in a Tropical Bird.

$451 \quad$ Ornitologia Neotropical 16: 253-262.

452 Roper, J.J. and R.R. Goldstein. 1997. A test of the Skutch hypothesis: does activity at nests 453 increase nest predation risk? Journal of Avian Biology 28: 111-116

454 Roper, J. J., K.A. Sullivan and R.E. Ricklefs. 2010. Avoid nest predation when predation rates 455 are low, and other lessons: testing the tropical-temperate nest predation paradigm. Oikos 119: 719-729.

457

458

459

460

461

462

463

464

465

466

467

468

469

470

Ruffino, L., Salvo, P., Koivisto, E., Banks, P.B. and E. Korpimaki. 2014. Reproductive responses of birds to experimental food supplementation: a meta-analysis. Frontiers in Zoology 11:80

Ruiz-Gutiérrez, V., Gavin, T.A. and Dhondt, A.A. 2008. Habitat Fragmentation Lowers Survival of a Tropical Forest Bird. Ecological Applications 18:838-46. doi:10.1890/07-1090.1.

Sinclair, K.E., G. R. Hess; C.E. Moormanb and J.H. Mason. 2005. Mammalian nest predators respond to greenway width, landscape context and habitat structure. Landscape and Urban Planning 71: 277-293.

Skutch, A.F. 1949. Do tropical birds rear as many young as they can nourish? Ibis 91: 430-455.

Skutch, A.F. 1985. Clutch size, nesting success, and predation on nests of neotropical birds, reviewed. p. 575-594. In: A. Buckley, M. S. Foster, E. S. Morton, R. S. Ridgley and F. G. Buckley (Eds.). Neotropical Ornithology. Allen Press, Lawrence.

Soler, M. and J.J. Soler. 1996. Effects of experimental food provisioning on reproduction in the Jackdaw Corvus monedula, a semi-colonial species. Ibis 138: 377-383. 
471 Stephens, P. A., Houston, A.I., Harding, K.C., Boyd, I.L., and McNamara, J.M. 2014. Capital

472 and Income Breeding: The Role of Food Supply. Ecology 95:882-96. doi 10.1890/13-

473 1434.1.

474

475

476

477

478

479

480

481

482

483

484

485

486

487

488

489

490

491

492

493

Stratford, J.A. and P.C. Stouffer. 2001. Reduced feather growth rates of two common birds inhabiting central Amazonian Forest fragments. Conservation Biology 15: 721-728.

Suarez A., K. S. Pfenning and S. K. Robinson. 1997. Nesting success of a disturbance-dependent songbird on different kinds of edges. Conservation Biology 11: 928-935.

Tewksbury, J. J., Hejl, S. J., and Martin, T. E. 1998. Breeding Productivity Does Not Decline with Increasing Fragmentation in a Western Landscape. Ecology 79:2890-2903. doi:10.1890/0012-9658(1998)079[2890:BPDNDW]2.0.CO;2.

Tewksbury, J. J., Garner, L., Garner, S., Lloyd, J. D., Saab, V., and Martin, T. E. 2006. Tests of landscape influence: nest predation and brood parasitism in fragmented ecosystems. Ecology 87: 759-768.

Vergara, P. M., and Hahn, I. 2009. Linking edge effects and patch size effects: Importance of matrix nest predators. Ecological Modelling, 220: 1189-1196.

Vergara, P. M., and Simonetti, J. A. 2004. Avian responses to fragmentation of the Maulino Forest in central Chile. Oryx, 38: 383-388.

Weinberg, H.J. and R.R. Roth. 1998. Forest area and habitat quality for nesting Wood Thrushes. Auk 115: 879-889.

White, G. C., and K. P. Burnham (1999). Program MARK: Survival estimation from populations of marked animals. Bird Study 46 (Supplement):S120-S139.

Zanette, L. and B. Jenkins. 2000. Nesting success and nest predators in forest fragments: a study using real and artificial nests. Auk 117: 445-454. 
494 Zanette, L., Smith, J.N.M., van Oort and M. Clinchy. 2003. Synergistic effects of food and 495 predators on annual reproductive success in song sparrows. Proceedings of the Royal 496 Society B. 270: 799-803.

497 Zanette, L.Y., A.F. White, M.C. Allen and M. Clinchy. 2011. Perceived predation risk reduces 498 the number of offspring songbirds produce per year. Science 334: 1398-1401.

499 Zimmer, K. \& Isler, M.L. (2003). Variable Antshrike (Thamnophilus caerulescens). In: del Hoyo, 500 J., Elliott, A., Sargatal, J., Christie, D.A. \& de Juana, E. (eds.) (2014). Handbook of the 501 Birds of the World Alive. Lynx Edicions, Barcelona. (retrieved from

502 http://www.hbw.com/node/56688 on 30 November 2014). 
Table 1. Comparison among the reproductive parameters, forest fragment size and supplemental food treatment.

\begin{tabular}{|c|c|c|c|c|c|c|}
\hline $\begin{array}{l}\text { Fragment } \\
\text { size (ha) }\end{array}$ & $\begin{array}{c}\text { Food } \\
\text { Treatment }\end{array}$ & Pairs (N) & $\begin{array}{c}\text { Nesting } \\
\text { attempts }(\mathrm{N})\end{array}$ & $\begin{array}{c}\text { Successes } \\
\text { (N) }\end{array}$ & $\begin{array}{l}\text { Nest DSR }{ }^{1} \\
\text { (SE) }\end{array}$ & $\begin{array}{c}\text { Renesting interval } \\
\text { days }^{2}\end{array}$ \\
\hline 24 & Control & 1 & 4 & 0 & & $35-38(3)$ \\
\hline 24 & Fed & 2 & 3 & 0 & $0.85(0.05)$ & $23(1)$ \\
\hline 112 & Control & 4 & 27 & 2 & $0.88(0.02)$ & $25-44(26)$ \\
\hline 112 & Fed & 4 & 40 & 3 & & $3-18(40)$ \\
\hline 214 & Control & 3 & 10 & 4 & $0.97(0.01)$ & $23-54(9)$ \\
\hline 214 & Fed & 5 & 19 & 13 & & $14-45(3)$ \\
\hline
\end{tabular}

${ }^{1}$ DSR was similar for control and fed treatments, but was greater in the large fragments $(\mathrm{P}<$ 0.05). ${ }^{2}$ Minimum and maximum intervals in days, number of nests in parentheses is different from the total number of nesting attempts because only intervals after failed nests are included. 
Table 2. Model comparison of the interactions between nesting success, fragment size and experimental food supplementation (Fig. 3). Fragment size had the lowest AICc value at 415.4

\begin{tabular}{ccc}
\hline Model & $\Delta$ AICc & Parameters \\
\hline Fragment Size & 0 & 3 \\
Fragment Size + Food & 2.2 & 6 \\
Food & 27.4 & 2 \\
Constant & 30.1 & 1
\end{tabular}


Table 3. Data-based simulation (100 runs of 30 simulated pairs) results with values used in the simulation (daily survival rate - DSR, clutch size - CS, breeding season length - BSL, renesting interval after failure and success), average number of nests pair ${ }^{-1}$ (Attempts) to achieve the resulting Productivity (average number of offspring pair ${ }^{-1}$ ), and the percentage of successful nests (Rate) and the probability of a second successful nest during the season ( $>1$ success). See figure 4 .

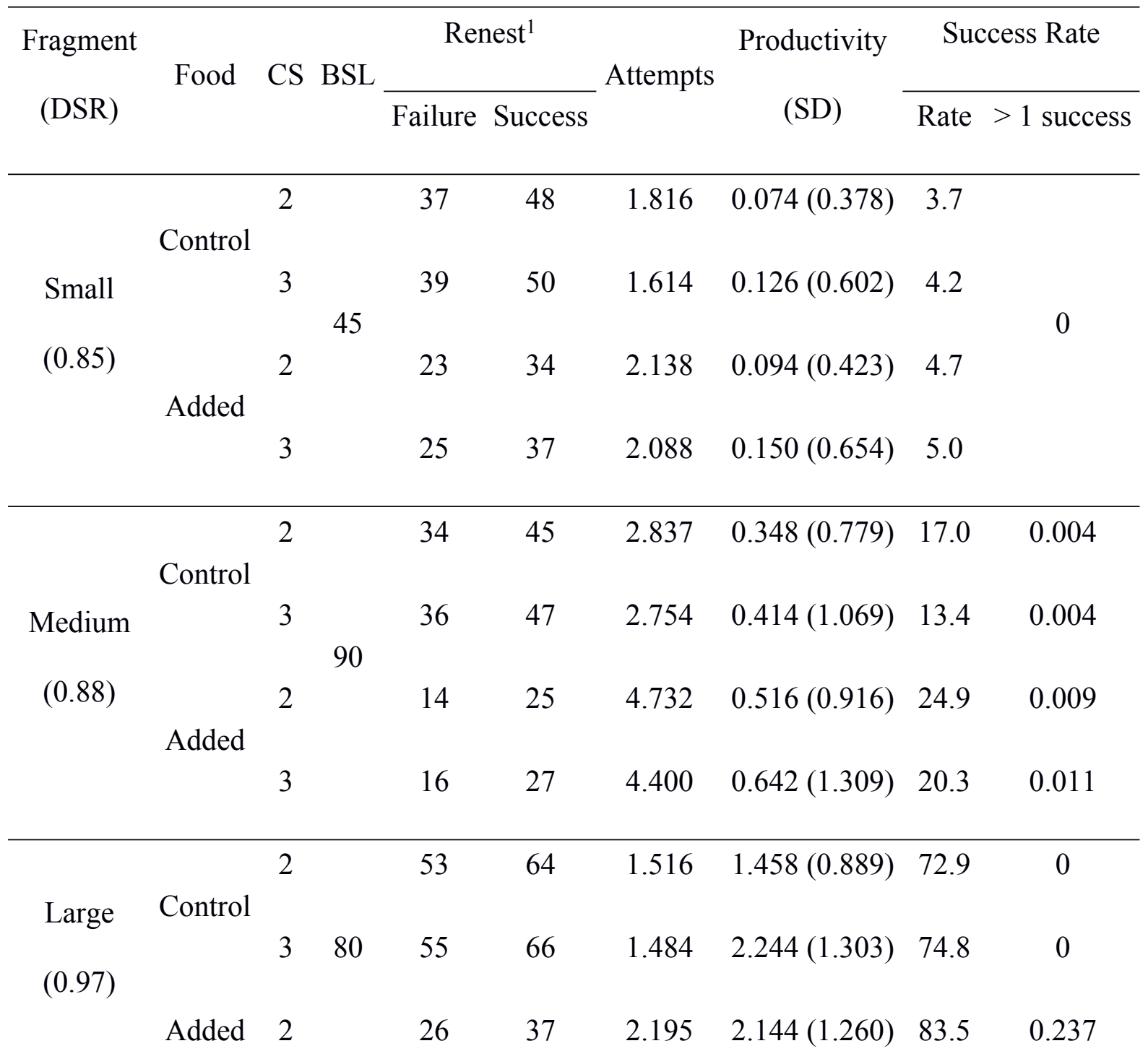


${ }^{1}$ Failed nests are the most common so we calculated renesting interval after failure for each treatment. Renesting interval after success was the average of all observed renesting intervals plus 11 days. We added a cost to 3 -egg clutches as two additional days in the nesting cycle, because egg laying occurs every other day. 
509 Figure Legends

510 Figure 1. A) Location of Vilha Velha State Park where this study took place, in southern Brazil.

511 B) Schematic map of the study area indicating the forest fragments included in this study.

512

513 Figure 2. Comparisons of the response to food treatments (control and added food) of A) daily

514 nest survival rates (mean, with 95\% confidence interval) and B) renesting intervals in days. Both

515 are compared by forest fragment sizes to illustrate interactions.

516

517 Figure 3. Comparison of the distributions of the number of nesting attempts expected based on

518 simulations of the consequences of natural (Control) and supplemented food based on the nesting

519 data in Table 3. Only birds with supplemented food can attempt more than three nests each 520 breeding season.

521

522 Figure 4. Average annual productivity (fecundity) based on a simulated 30 pairs (a field

523 population) and the breeding parameters described in this study (Table 3), compared between

524 fragment sizes and experimental food treatments (A - 214 ha. fragment, B - 112 ha fragment, C

$525-24$ ha fragment). Increase fecundity in the largest fragment is a consequence of both reduced

526 predation rates and food treatments. Note that the increased clutch size came at a cost of reduced

527 time in which to breed, so while three-egg clutches produced more, the increase was not simply

528 additive. The average productivity in both smaller fragments was less than one offspring per pair

529 per year, and many "populations" (50\% in the smallest fragment) were never successful. 


\section{Figure 1.}

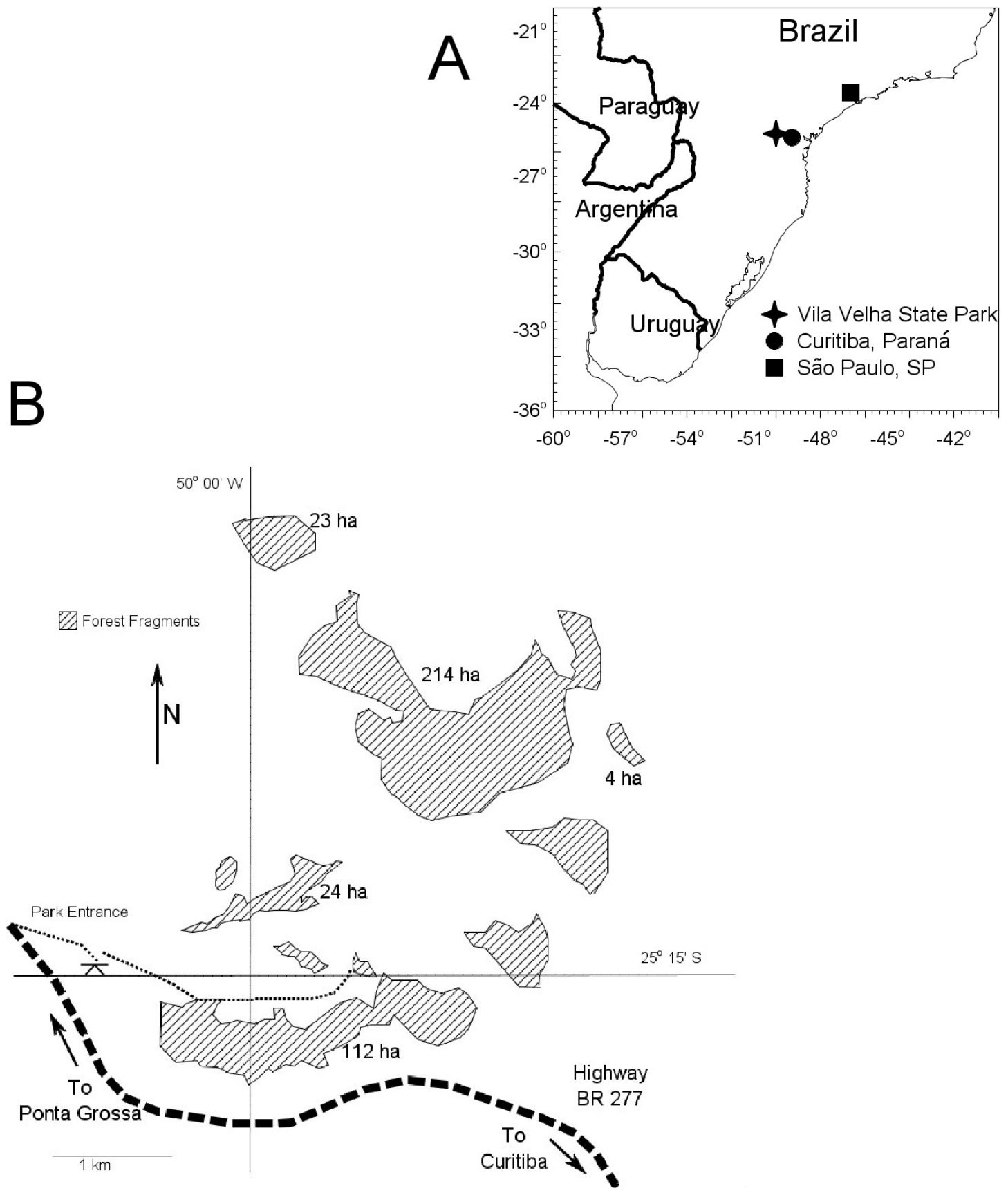


532 Figure 2.

533

534
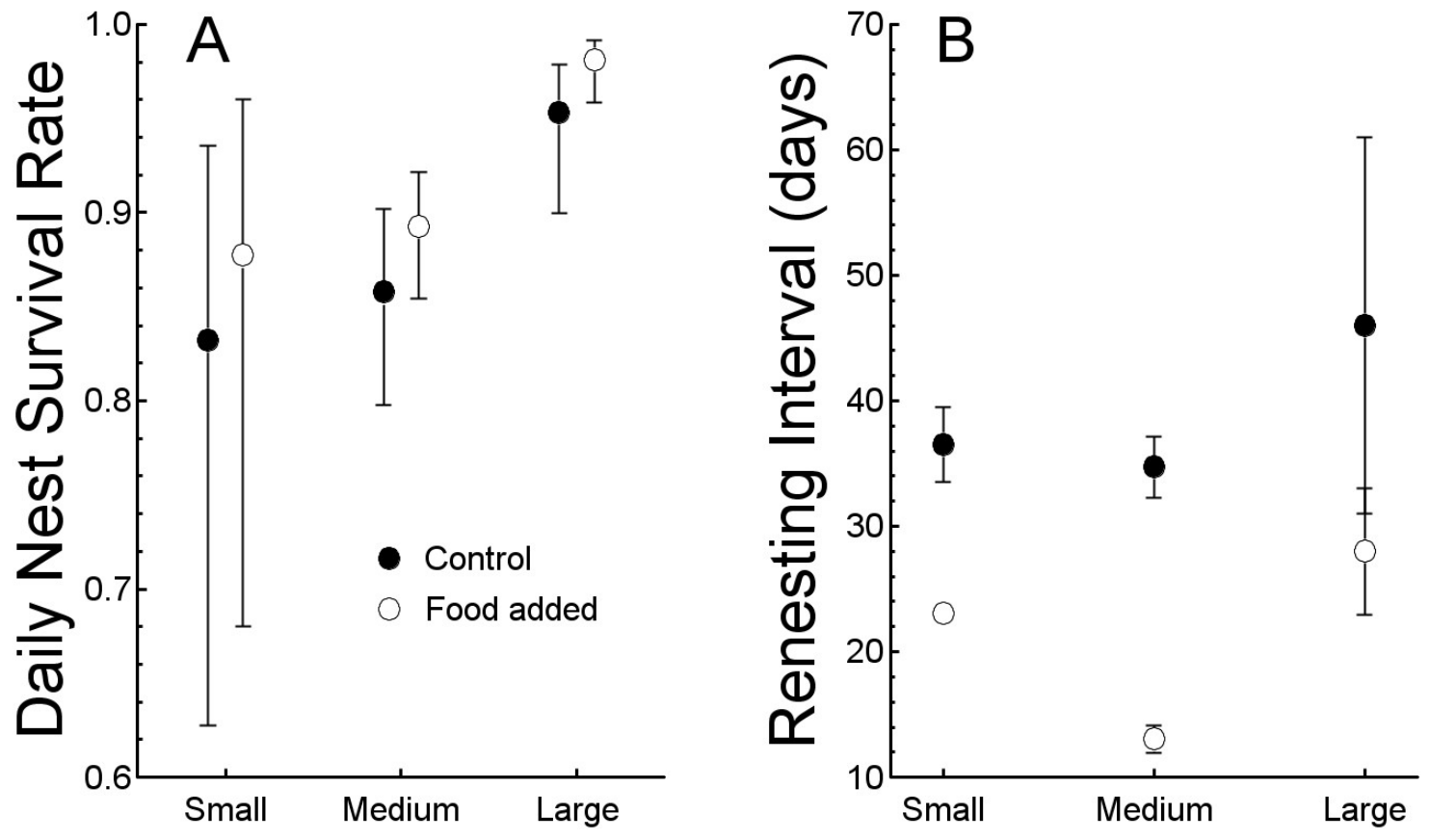

Fragment Size 
535 Figure 3.

536

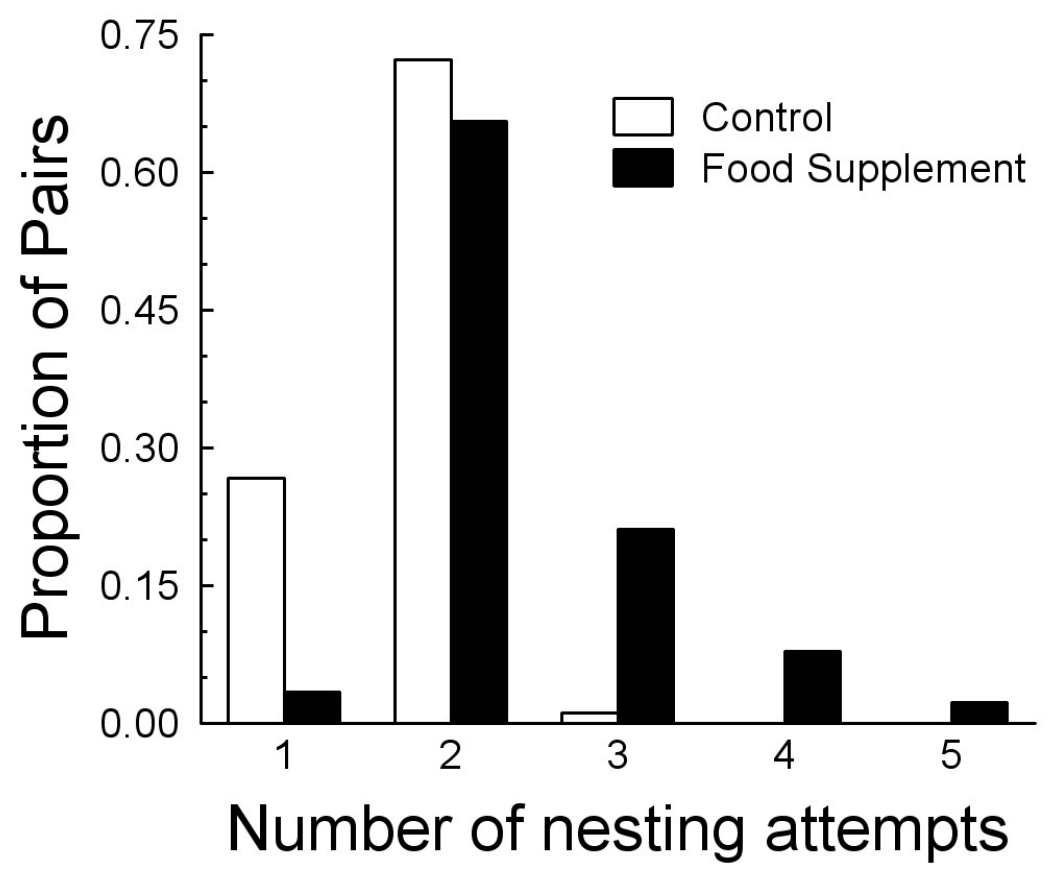


537 Figure 4.

538

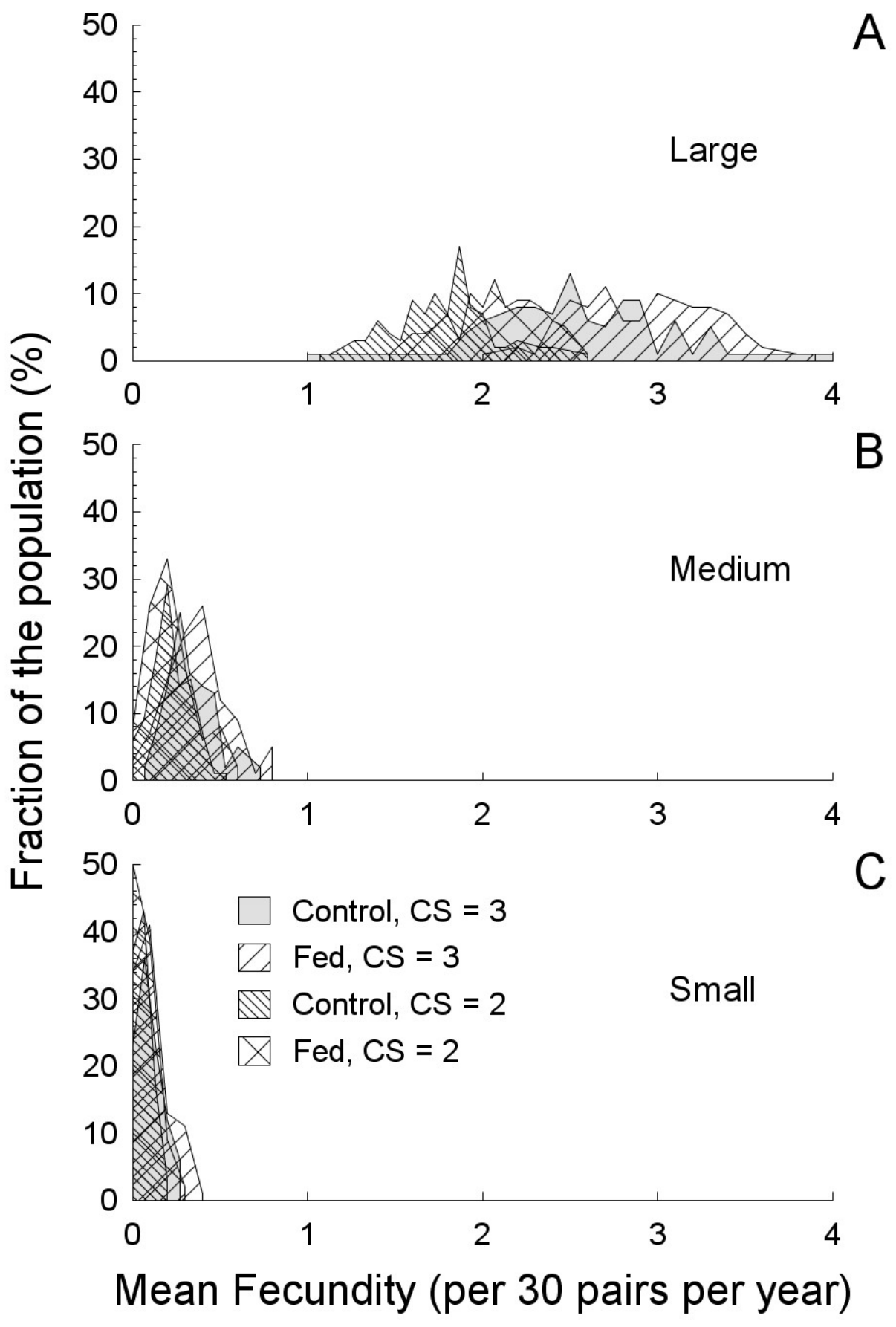

